\title{
A Conceptual Framework in the Study of Neuropsychological Development in Epidemiological Studies
}

\author{
J. Forns ${ }^{a-c}$ A. Aranbarrid, e J. Grellier ${ }^{a-c, f} \quad$ J. Julvez ${ }^{a-c, f} \quad$ M. Vrijheid ${ }^{a-c}$ \\ J. Sunyer ${ }^{a-c, g}$
}

${ }^{a}$ Centre for Research in Environmental Epidemiology, ${ }^{b}$ Hospital del Mar Research Institute, and ${ }^{\mathrm{C} C I B E R}$ Epidemiologia y Salud Pública, Barcelona, dPsychobiology Area, Basic Psychological Processes and Development Department, Faculty of Psychology, University of the Basque Country, and eBioDonostia Health Research Institute, Donostia, Spain; ' Department of Epidemiology and Biostatistics, Imperial College London, London, UK; gDepartment of Environmental Health, Harvard School of Public Health, Boston, Mass., USA

\section{Key Words}

Cognitive assessment $\cdot$ Cohort studies $\cdot$ Epidemiological studies • Neuropsychological assessment

\section{Abstract \\ Background: A wide range of neuropsychological develop- ment outcomes in children are currently measured in a large number of birth cohort and child cohort studies. Methods: We summarized neuropsychological development assess- ment protocols from a number of birth cohort studies, re- views and specific books on child neuropsychology into a unifying conceptual framework. Results: We suggest that neuropsychological development can be differentiated into two levels, i.e. functional and clinical. The functional level includes the skills, abilities, capacities and knowledge ac- quired during maturation of the brain as a result of the de- velopment of neural networks. It can be further divided into cognitive, psychomotor and social-emotional development subdomains. The clinical level includes the assessment of neurodevelopmental disorders or the presence of symp- toms (subclinical symptomatology) of these disorders in}

populations under investigation in environmental epidemiology studies. Conclusions: Through explicit recognition of these levels of outcomes, and in using this framework, epidemiologists will be better able to design research through the informed selection of individual levels of outcomes. The framework also serves to standardize disparate terminologies across this field and allows for pooling of epidemiological data on neuropsychological endpoints where essentially similar levels of outcomes have been analyzed using different tests.

Copyright $\odot 2012$ S. Karger AG, Basel

\section{Introduction}

The developing human brain is extremely sensitive to some environmental factors such as certain industrial chemicals, tobacco smoke, alcohol and certain drugs, as well as low socioeconomic status, elevated maternal stress, negative parenting behaviors or family violence [1]. This vulnerability is particularly important during early development, but it extends through infancy and child-

\section{KARGER \\ Fax +4161306 1234 \\ E-Mail karger@karger.ch}

www.karger.com (c) 2012 S. Karger AG, Basel

0251-5350/12/0384-0203\$38.00/0

Accessible online at:

www.karger.com/ned
Joan Forns Guzmán

Centre for Research in Environmental Epidemiology - IMIM

C. Doctor Aiguader 88

ES-08003 Barcelona (Spain)

Tel. +34 93214 7311, E-Mail jforns@ @real.cat 
hood [2]. Both the prenatal period and the first year of life represent critical phases in the early development of neural networks and their associated cognitive and psychomotor functions. During the postnatal period, the brain requires a particularly large complement of nutrients due to its high metabolic activity, especially for the development of certain areas of the cortex [3]. The susceptibility of infants and children to many exogenous compounds is accounted for by their low capacity to detoxify them [2, 4]. For these reasons, the developing central nervous system represents the bodily system most commonly disrupted by environmental teratogenic agents [5]. However, the developing brain is not only exposed to environmental agents but is also affected by a number of social factors that play a crucial role in the neuropsychological development process. These social influences chiefly comprise parental characteristics, such as cognitive capacities, social class or mental health. Such parental and social characteristics influence some important aspects of child development, such as quality of nutrition, health care, housing and the provision of a cognitively stimulating environment $[6,7]$.

The developing brain is a highly complex organ, and its development is a genetically driven process modulated by social and environmental factors [8]. Successful brain development requires that each area first be formed and then be correctly interrelated with the others [9]. Thus, a highly structured and complex approach is needed to accurately measure this process. An optimal assessment of the neuropsychological development process is crucial to the detection of subtle or more obvious effects of the environment on this process because the integrity of the whole system may be compromised if a sole specific domain is affected. The long-term consequences of these alterations may be important at the individual and population levels. For this reason, it is important to understand normal brain development to identify any abnormal differences.

The first attempts at studying associations between exposure to chemical agents and child neuropsychological development were reported in the 1970s [10, 11]. Since that time, research in environmental epidemiology has increasingly turned its attention towards the developing human brain. As a result, a wide range of neuropsychological development outcomes in children are now measured in many birth and child cohort studies. The aim of this work was to synthesize information on neuropsychological assessment protocols from a number of environmental epidemiological studies into a single practical and conceptual framework.

\section{Methods}

Firstly, as part of the Environmental Health Risks in European Birth Cohorts (ENRIECO) Project (www.enrieco.org), we reviewed the assessment protocols for neuropsychological development in all of the European longitudinal birth cohorts involved in this project that currently collect data on environmental exposures and child health. Twenty-five cohorts were identified which assess child neuropsychological development prospectively from birth to later adolescence (depending on the starting point of each cohort). These European birth cohorts were not designed according to a common protocol, and therefore the ages of assessment and the neuropsychological developmental areas evaluated differ among cohorts. However, in all cohorts children were assessed at least once in the first 2 years of life, in the preschool period and before adolescence. The most commonly used tests in the ENRIECO cohorts at these different ages were the Bayley Scales of Infant Development [12], the McCarthy Scales of Children's Abilities [13]/Wechsler Preschool and Primary Scale of Intelligence [14] and the Wechsler Intelligence Scale for Children [15]. All of them are tests assessing general neuropsychological development, albeit covering different neuropsychological domains.

Secondly, we reviewed the neuropsychological development assessment protocol of the National Children's Study from the USA [16-20]. This protocol was elaborated by a panel of experts in this area and was designed to assess the children once every year between the ages of 6 months and 20 years. Thirdly, we reviewed relevant reviews of the neuropsychological developmental literature within the epidemiological field. We used several electronic databases [PubMed (http://www.ncbi.nlm.nih.gov/pubmed), PsycINFO (http://www.apa.org/pubs/databases/psycinfo/ index.aspx) and Web of Knowledge (http://apps.isiknowledge. com)] to conduct the initial literature search. Using a combination of the keywords 'birth cohort studies' and one of either 'neuropsychology', 'child development', 'cognitive assessment', 'neurodevelopmental' or 'neurobehavioral', we then selected relevant reviews that summarized the whole or some specific areas of neuropsychological development [3, 21-28]. Lastly, we reviewed some recently published books dedicated to child neuropsychological development $[9,29,30]$.

\section{Results}

Figure 1 represents the conceptual framework of child neuropsychological development that we assembled as a result of our review. Two levels of outcomes can be differentiated, i.e. functional and clinical (table 1). The functional level refers to the skills, abilities, capacities and/or knowledge acquisition acquired during maturation of the brain and its interaction with the social and educational environment. These abilities increase their complexity over time as a result of the development of neural networks in the cortex, which allow the individual to adapt to the increasing demands of the environment. There are three domains at this functional level, i.e. cognitive, psy- 


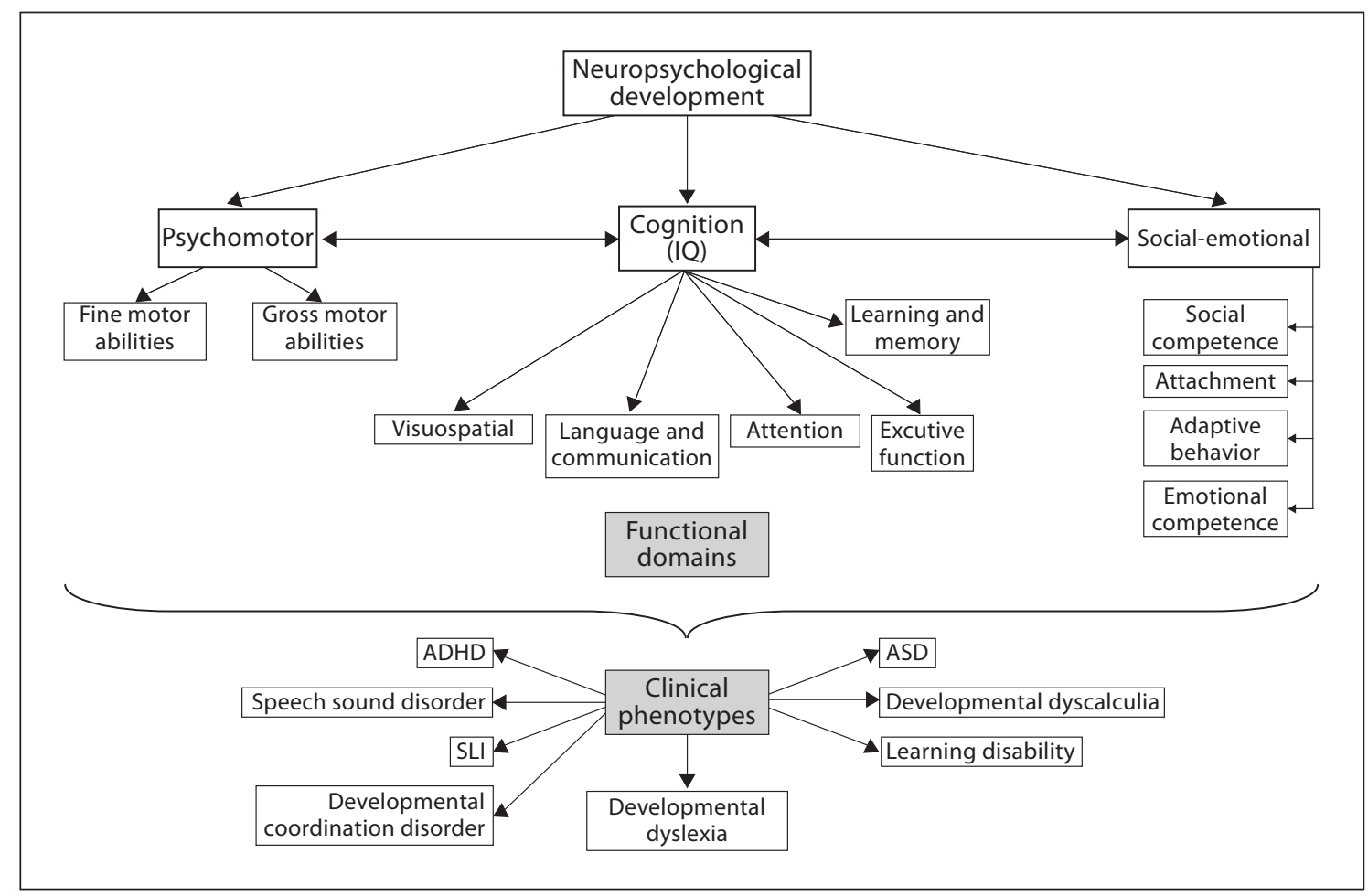

Fig. 1. Conceptual framework of the neuropsychological developmental process. SLI = Specific language impairment; $\mathrm{ADHD}=$ attention deficit hyperactivity disorder; $\mathrm{ASD}=$ autistic spectrum disorder.

chomotor and social-emotional. These three domains are highly overlapped and interrelated. Their development is dependent on one another, and a nonoptimal (or pathological) development of one of them may have implications for the rest of the domains.

Cognitive function can be conceptualized as a hierarchic model, where specific cognitive domains such as attention, language and executive functions, among others, are posited beneath the overarching domain of general cognition (table 1). Such cognitive domains should be assessed by trained neuropsychologists through the use of age-appropriate standardized neuropsychological tests. A trained neuropsychologist is also required to accurately interpret child neuropsychological assessment data. Each one of these cognitive domains can also be divided into several subdomains. This is especially critical in the case of executive functions because they are understood as a set of cognitive skills that are responsible for the planning, initiation, sequencing and monitoring of complex goal-directed behavior. The psychomotor domain can be divided into fine and gross motor skills; these are usually assessed by neuropsychological tests or by way of questionnaires. The social-emotional domain refers to the ability to regulate emotions appropriately and to relate to others. This level has typically received the least attention, even though it encompasses several aspects of adaptive behavioral development; we argue that this area merits considerably more attention in birth cohorts because of the potential long-term consequences of poor social development in terms of unemployment, mental health issues, marital difficulties, unadaptive behaviors, delinquency or violence. The social-emotional domain is typically assessed using psychological questionnaires filled in through interviews with parents or teachers, which provide information on various characteristics of child behavior that occur in the ecological environment in which the child is developing (i.e. at home and at school).

Clinical phenotypes refer to some neurodevelopmental disorders or the presence of symptoms of these disorders in the population scrutinized in environmental epidemiology studies (subclinical symptomatology). The term neurodevelopmental disorder is usually used in one of two ways, describing either those conditions affecting neuropsychological development in children with a known genetic etiology (e.g. fragile X syndrome) or those conditions ascribed to presumed multifactorial etiologies 
Table 1. Definition of different subphenotypes

\begin{tabular}{|c|c|c|c|c|}
\hline Outcome & Sublevel & Specific domain & Definition & Reference \\
\hline \multirow[t]{10}{*}{ Functional } & \multirow[t]{5}{*}{ cognitive } & attention & $\begin{array}{l}\text { 'This domain encompasses several processes including the capacity to focus on and } \\
\text { attend to stimuli over a period of time and the capacity to take in and report back stimuli } \\
\text { immediately after presentation.' }\end{array}$ & $\begin{array}{l}\text { White et al. } \\
{[19]}\end{array}$ \\
\hline & & language & $\begin{array}{l}\text { 'This domain includes basiclinguistic abilities such as the capacity to produce phonemes, } \\
\text { lexical development, production of words and language structure development } \\
\text { (grammar), speech comprehension and linguistic aspects of writing and reading. } \\
\text { Language skills are often divided into expressive and receptive components.' }\end{array}$ & $\begin{array}{l}\text { White et al. } \\
\text { [19] }\end{array}$ \\
\hline & & $\begin{array}{l}\text { executive } \\
\text { function }\end{array}$ & $\begin{array}{l}\text { 'Metacognitive capacities that allow an individual to perceive stimuli from his or her } \\
\text { environment, respond adaptively, flexibly change direction, anticipate future goals, } \\
\text { consider consequences, and respond in an integrated or common-sense way, utilizing } \\
\text { all these capacities to serve a common purposive goal.' }\end{array}$ & Baron [29] \\
\hline & & $\begin{array}{l}\text { learning and } \\
\text { memory }\end{array}$ & $\begin{array}{l}\text { 'Memory terms are classified in a number of ways. Among these are reference to } \\
\text { whether there is conscious awareness of recall (explicit or declarative memory vs. } \\
\text { implicit or procedural memory); central stages or features (encoding, consolidation, } \\
\text { storage, retrieval); consideration of a time-interval span (immediate, short-term, or } \\
\text { long-term, the latter including recent and remote memory); specific memory } \\
\text { impairment (anterograde amnesia, retrograde amnesia); or by characteristics related to } \\
\text { the recall (prospective memory, source memory).' }\end{array}$ & Baron [29] \\
\hline & & $\begin{array}{l}\text { visuospatial } \\
\text { abilities }\end{array}$ & $\begin{array}{l}\text { 'These non-verbal abilities generally invoke the processing and manipulation of visual } \\
\text { designs, the spatial or physical aspects of environmental objects or constructional skills.' }\end{array}$ & $\begin{array}{l}\text { White et al. } \\
{[19]}\end{array}$ \\
\hline & psychomotor & & $\begin{array}{l}\text { 'Psychomotor functions cover a broad range of morphologically and functionally } \\
\text { different phenomena. Functions range from highly automised gross motor activities } \\
\text { like walking to highly skilled fine motor skills like knitting or running a computer } \\
\text { program by highly skilled, precisely located mouse clicks.' }\end{array}$ & $\begin{array}{l}\text { Kallus et al. } \\
{[33]}\end{array}$ \\
\hline & \multirow[t]{4}{*}{ social-emotional } & $\begin{array}{l}\text { social } \\
\text { competence }\end{array}$ & 'Effectiveness in developmentally appropriate social interactions.' & $\begin{array}{l}\text { Denham } \\
\text { et al. [16] }\end{array}$ \\
\hline & & attachment & $\begin{array}{l}\text { 'Attachment begins as the deep and enduring connection established between a child } \\
\text { and his/her caregiver in the first several years of life.' }\end{array}$ & $\begin{array}{l}\text { Denham } \\
\text { et al. [16] }\end{array}$ \\
\hline & & $\begin{array}{l}\text { adaptive } \\
\text { behavior }\end{array}$ & $\begin{array}{l}\text { 'The development of the adaptive behavior involves the regulation of the other behaviors } \\
\text { to the social rules and to the demands of the context surrounding the child.' }\end{array}$ & Saarni [34] \\
\hline & & $\begin{array}{l}\text { emotional } \\
\text { competence }\end{array}$ & $\begin{array}{l}\text { 'The multifaceted ability strategically to be aware of one's own and others' emotions and } \\
\text { to act on this awareness, to negotiate interpersonal exchanges and regulate emotional } \\
\text { experience.' }\end{array}$ & $\begin{array}{l}\text { Denham } \\
\text { et al. [16] }\end{array}$ \\
\hline \multirow[t]{8}{*}{ Clinical } & \multicolumn{2}{|l|}{ ADHD } & $\begin{array}{l}\text { 'ADHD is defined by problems with inattention and/or hyperactivity/impulsivity, with } \\
\text { onset before the age of } 7 \text { years and resultant impairment in two or more settings.' }\end{array}$ & $\begin{array}{l}\text { McClellan } \\
\text { et al. [18] }\end{array}$ \\
\hline & \multicolumn{2}{|l|}{$\begin{array}{l}\text { speech sound } \\
\text { disorder }\end{array}$} & $\begin{array}{l}\text { 'Children with SSD are delayed in the acquisition of developmentally appropriate } \\
\text { speech sounds, resulting in reduced speech intelligibility. Idiopathic SSD is not due to } \\
\text { known etiological factors such as cleft palate or hearing loss and is limited to disorders } \\
\text { of speech sound production (i.e. not stuttering).' }\end{array}$ & $\begin{array}{l}\text { Raitano } \\
\text { et al. [35] }\end{array}$ \\
\hline & \multicolumn{2}{|l|}{ SLI } & $\begin{array}{l}\text { 'Selective failure to develop language at a normal rate in the absence of frank neurological } \\
\text { and psychiatric disease and adequate educational opportunity.' }\end{array}$ & $\begin{array}{l}\text { Tranel and } \\
\text { de Haan [36] }\end{array}$ \\
\hline & \multicolumn{2}{|l|}{$\begin{array}{l}\text { developmental } \\
\text { coordination disorder }\end{array}$} & $\begin{array}{l}\text { 'Is characterized by motor impairment that interferes with the child's activities of daily } \\
\text { living and academic achievement.' }\end{array}$ & $\begin{array}{l}\text { Dewey and } \\
\text { Wilson [37] }\end{array}$ \\
\hline & \multicolumn{2}{|l|}{$\begin{array}{l}\text { developmental } \\
\text { dyslexia }\end{array}$} & $\begin{array}{l}\text { 'Developmental dyslexia, or specific reading disability, is defined as an unexpected, } \\
\text { specific, and persistent failure to acquire efficient reading skills despite conventional } \\
\text { instruction, adequate intelligence, and sociocultural opportunity.' }\end{array}$ & $\begin{array}{l}\text { Démonet } \\
\text { et al. [38] }\end{array}$ \\
\hline & \multicolumn{2}{|l|}{$\begin{array}{l}\text { intellectual disability/ } \\
\text { learning disability }\end{array}$} & $\begin{array}{l}\text { 'This can be both a "symptom of a known disorder, and a non-syndromal condition of } \\
\text { unknown etiology". Furthermore, in the UK, the term "learning disability" is used to } \\
\text { refer to intellectual disability, whereas elsewhere "learning disability" is used for specific } \\
\text { difficulties in a child of normal IQ.' }\end{array}$ & Bishop [32] \\
\hline & \multicolumn{2}{|l|}{$\begin{array}{l}\text { developmental } \\
\text { dyscalculia }\end{array}$} & $\begin{array}{l}\text { 'Is defined by difficulty in learning and remembering arithmetic facts and in executing } \\
\text { calculation procedures, with immature problem solving strategies, long solution times } \\
\text { and high error rates.' }\end{array}$ & Geary [39] \\
\hline & \multicolumn{2}{|l|}{ ASD } & $\begin{array}{l}\text { 'Autism spectrum disorders (ASDs) encompass the diagnoses of autism disorder, PDD- } \\
\text { NOS and Asperger's syndrome. Children with these disorders often have life-long } \\
\text { difficulties with their ability to communicate and socially relate to others.' }\end{array}$ & $\begin{array}{l}\text { McClellan } \\
\text { et al. [18] }\end{array}$ \\
\hline
\end{tabular}

SSD = Speech sound disorder; SLI = specific language impairment; ADHD = attention deficit hyperactivity disorder; ASD = autistic spectrum disorder; PDD-NOS = pervasive developmental disorder not otherwise specified. 
in which certain domains of neuropsychological development are selectively impaired [e.g. attention deficit hyperactivity disorder (ADHD)] [31]. The process of selecting disorders for inclusion in figure 1 was not straightforward. Based on publication rates, the most extensively studied neurodevelopmental disorders are ADHD and autistic spectrum disorders. However, it is misleading to focus only on certain disorders. In figure 1 we include the eight most prevalent neurodevelopmental disorders as reported by Bishop [32]. In order of decreasing prevalence, these disorders are: speech sound disorder, specific language impairment, developmental coordination disorder, developmental dyslexia, intellectual and learning disability, ADHD, developmental dyscalculia and autistic spectrum disorders. Environmental epidemiology has the potential to shed light on many such high-prevalence neurodevelopmental disorders in the general population which currently garner little attention. These disorders may have associated consequences such as low achievement in school, behavioral adaptation (school, professional and personal), diminished economic productivity and possibly an increased risk of antisocial and criminal behavior. As such, they may contribute to the so-called 'silent pandemic' proposed by Grandjean and Landrigan [2]. Neurodevelopmental disorders are usually assessed not only by psychological tests based on diagnostic criteria of mental disorders but also by structured interviews and questionnaires. However, in environmental epidemiology, it would be preferable to assess the continuum of symptoms (subclinical symptomatology) associated with such disorders rather than assessing the presence of these diagnoses as defined by clinical cutoffs.

\section{Discussion}

This framework serves as a starting point for the standardization of the relevant terminology and thereby facilitates the choice of phenotypes in future epidemiological studies. The lack of a common framework for the study of neuropsychological development in environmental epidemiology studies, and a concomitant lack of consistency in the associated terminology, currently hinders research collaboration and the setting of targets. We have summarized the work carried out so far in this increasingly relevant area in order to meet several objectives. This framework will allow epidemiologists with little expertise in this topic to better understand the area of neuropsychological development assessed in a specific study. Moreover, it will enable better design of future re- search and foster better informed selection of the outcomes of interest. The development of this conceptual framework may also serve as a starting point towards standardizing the terminology used in the neuropsychological development field and for specific outcomes encountered in environmental epidemiology literature.

It is notable that very few neuropsychologists work in the field of environmental epidemiology. The presence of these professionals with a background in both neurodevelopment and neuropsychological development is critical to the elaboration and application of assessment protocols (based on their knowledge of brain development and neuropsychological testing), to quality control in data collection and analysis and to the interpretation of study findings. Their inclusion in multidisciplinary research teams may improve the quality of research in this important field.

The conceptual framework presented herein also provides a theoretical justification for the conduct of pooled or meta-analyses of cohort studies that use different tests in assessing the same phenotypes. The majority of functional domains may be divided into a set of specific subdomains. Clearly, a cautious and robust approach is needed in order to combine the data in a meaningful way, particularly in pooled analyses, where an a priori theoretical background and statistical modelling are employed. Sensible combination of data originating from different neuropsychological tests is highly dependent on the specificity of the effects of particular environmental agents on neuropsychological development. Again, the importance of involving neuropsychologists is paramount since it is only with their understanding of the relevant tests and cognitive functions that we may advance in this field.

The publication of this framework marks a synthesis of the highly complex processes of neuropsychological development in a unified practical and conceptual framework.

\section{Acknowledgement}

ENRIECO was funded by the European Union's 7th Framework Programme (FP7-ENV-2008-226285) to coordinate birth cohort research in Europe in the area of environmental contaminant exposures (www.enrieco.org).

\section{Disclosure Statement}

The authors declare that they have no competing interests. 


\section{References}

$>1$ Julvez J, Grandjean P: Neurodevelopmental toxicity risks due to occupational exposure to industrial chemicals during pregnancy. Ind Health 2009;47:459-468.

$>2$ Grandjean P, Landrigan PJ: Developmental neurotoxicity of industrial chemicals. Lancet 2006;368:2167-2178.

-3 Johnson MH: Functional brain development in humans. Nat Rev Neurosci 2001;2:475483.

4 Ginsberg G, Hattis D, Sonawane B: Incorporating pharmacokinetic differences between children and adults in assessing children's risks to environmental toxicants. Toxicol Appl Pharmacol 2004;198:164-183.

5 Rodier PM: Vulnerable periods and processes during central nervous system development. Environ Health Perspect 1994; 102(suppl 2):121-124.

$\checkmark 6$ Francis DD, Diorio J, Plotsky PM, Meaney MJ: Environmental enrichment reverses the effects of maternal separation on stress reactivity. J Neurosci 2002;22:7840-7843.

7 Rosales FJ, Reznick JS, Zeisel SH: Understanding the role of nutrition in the brain and behavioral development of toddlers and preschool children: identifying and addressing methodological barriers. Nutr Neurosci 2009; 12:190-202.

$>8$ Casey BJ, Tottenham N, Liston C, Durston $\mathrm{S}$ : Imaging the developing brain: what have we learned about cognitive development? Trends Cogn Sci 2005;9:104-110.

9 Reynolds CR, Fletcher-Janzen E (eds): Handbook of Clinical Child Neuropsychology, ed 3. New York, Springer, 2009.

-10 Landrigan PJ, Whitworth RH, Baloh RW, Staehling NW, Barthel WF, Rosenblum BF: Neuropsychological dysfunction in children with chronic low-level lead absorption. Lancet 1975;1:708-712.

-11 Needleman HL, Gunnoe C, Leviton A, Reed $\mathrm{R}$, Peresie H, Maher C, et al: Deficits in psychologic and classroom performance of children with elevated dentine lead levels. N Engl J Med 1979;300:689-695.

12 Bayley N: Manual for the Bayley Scales of Infant Development, ed 2. San Antonio, The Psychological Corporation, 1993.

13 McCarthy D: MSCA. Escalas McCarthy de Aptitudes y Psicomotricidad para Niños. Madrid, TEA Ediciones, 2009.
14 Wechsler D: WPPSI-III Administration and Scoring Manual. San Antonio, The Psychological Corporation, 2002.

15 Wechsler D: WISC-IV Administrative and Scoring Manual. San Antonio, The Psychological Corporation, 2003.

16 Denham SA, Wyatt TM, Bassett $\mathrm{HH}$ Echeverria D, Knox SS: Assessing socialemotional development in children from a longitudinal perspective. J Epidemiol Community Health 2009;63(suppl 1):i37-i52.

17 Knox SS, Echeveria D: Methodological issues related to longitudinal epidemiological assessment of developmental trajectories in children. J Epidemiol Community Health 2009;63(suppl 1):i1-i3.

18 McClellan J, Bresnahan MA, Echeverria D, Knox SS, Susser E: Approaches to psychiatric assessment in epidemiological studies of children. J Epidemiol Community Health 2009;63(suppl 1):i4-i14.

19 White RF, Campbell R, Echeverria D, Knox SS, Janulewicz P: Assessment of neuropsychological trajectories in longitudinal population-based studies of children. J Epidemiol Community Health 2009;63(suppl 1):i15i26.

20 Rosenbaum PL, Missiuna C, Echeverria D, Knox SS: Proposed motor development assessment protocol for epidemiological studies in children. J Epidemiol Community Health 2009;63(suppl 1):i27-i36.

-21 Dietrich KN, Eskenazi B, Schantz S, Yolton K, Rauh VA, Johnson CB, et al: Principles and practices of neurodevelopmental assessment in children: lessons learned from the Centers for Children's Environmental Health and Disease Prevention Research. Environ Health Perspect 2005;113:14371446.

22 Isaacs E, Oates J: Nutrition and cognition: assessing cognitive abilities in children and young people. Eur J Nutr 2008;47(suppl 3):424.

23 Winneke G: Appraisal of neurobehavioral methods in environmental health research: the developing brain as a target for neurotoxic chemicals. Int J Hyg Environ Health 2007;210:601-609.

24 Roeder MB, Mahone EM, Gidley Larson J, Mostofsky SH, Cutting LE, Goldberg MC, et al: Left-right differences on timed motor examination in children. Child Neuropsychol 2008;14:249-262.
25 Nikolić SJ, Ilić-Stosović DD: Detection and prevalence of motor skill disorders. Res Dev Disabil 2009;30:1281-1287.

26 Andrews G, Pine DS, Hobbs MJ, Anderson TM, Sunderland M: Neurodevelopmental disorders: cluster 2 of the proposed metastructure for DSM-V and ICD-11. Psychol Med 2009;39:2013-2023.

27 Johnson CP, Myers SM: Identification and evaluation of children with autism spectrum disorders. Pediatrics 2007;120:1183-1215.

28 Tieman BL, Palisano RJ, Sutlive AC: Assessment of motor development and function in preschool children. Ment Retard Dev Disabil Res Rev 2005;11:189-196.

29 Baron I: Neuropsychological Evaluation of the Child, ed 1. New York, Oxford University Press, 2004.

30 Semrud-Clikeman M, Teeter Ellison P (eds): Child Neuropsychology, ed 2. New York, Springer, 2009

31 Bishop D, Rutter M: Neurodevelopmental Disorders: Conceptual Approaches. Oxford, Blackwell, 2008.

32 Bishop DVM: Which neurodevelopmental disorders get researched and why? PLoS One 2010;5:e15112.

33 Kallus KW, Schmitt JAJ, Benton D: Attention, psychomotor functions and age. Eur J Nutr 2005;44:465-484.

34 Saarni C: Emotional competence: how emotions and relationships become integrated. Nebr Symp Motiv 1988;36:115-182.

35 Raitano NA, Pennington BF, Tunick RA Boada R, Shriberg LD: Pre-literacy skills of subgroups of children with speech sound disorders. J Child Psychol Psychiatry 2004; 45:821-835.

36 Tranel D, de Haan E: Selective developmental neuropsychological disorders. Cortex 2007;43:667-671.

37 Dewey D, Wilson BN: Developmental coordination disorder: what is it? Phys Occup Ther Pediatr 2001;20:5-27.

38 Démonet J-F, Taylor MJ, Chaix Y: Developmental dyslexia. Lancet 2004;363:14511460.

>39 Geary DC: Mathematical disabilities: cognitive, neuropsychological, and genetic components. Psychol Bull 1993;114:345-362. 